\title{
T-cell lymphoma in a man with persistent dyspnea and unusual dependent pulmonary interstitial thickening
}

\author{
James P McDonald, ${ }^{1}$ Nathan L Law, ${ }^{2}$ John A Haggstrom, ${ }^{1}$ Matthew J Kruse ${ }^{1}$
}

${ }^{1}$ Radiology, Creighton University School of Medicine, Omaha, Nebraska, USA

${ }^{2}$ Creighton University School of Medicine, Omaha, Nebraska, USA

\section{Correspondence to} Dr Matthew J Kruse; MatthewKruse@creighton.edu

Accepted 22 April 2021

\section{DESCRIPTION}

A 43-year-old previously healthy man with hypertension presented to his primary care provider with fevers and dyspnea, after a history of cough and sinus congestion lasting several weeks. A chest radiograph demonstrated prominent interstitial markings with scattered alveolar opacities. Based on the clinical and radiographic findings, the patient began treatment with broad spectrum antibiotics for presumed pneumonia.

Four days later, the patient presented to the emergency department with worsening dyspnea and was found to have $\mathrm{SpO}_{2} 87 \%$ on room air, sinus tachycardia with heart rate 107 beats/min and elevated venous lactic acid of $5.1 \mathrm{mmol} / \mathrm{L}$. CT of the chest was obtained (figure 1), demonstrating peribronchovascular and interlobular interstitial thickening in the dependent lungs. Nodular thickening of the peribronchovascular interstitium raised the possibility of lymphoproliferative disease. ${ }^{12}$ The appearance was overall considered non-specific, and atypical community acquired pneumonia was favored given the predominant dependent distribution. After several days without improvement,

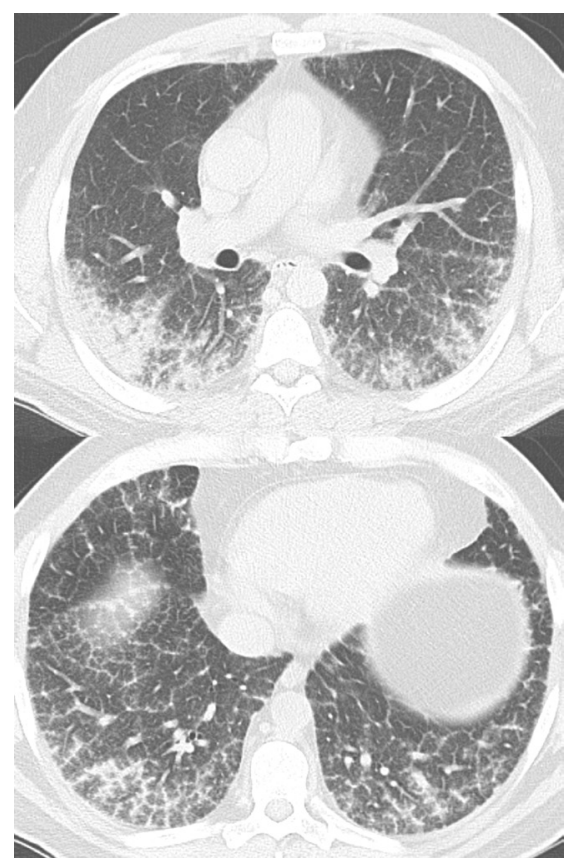

Figure 1 Initial axial CT images demonstrate dependent peribronchovascular and interlobular interstitial thickening. There is a nodular appearance of the peribronchovascular interstitium. he developed leukocytosis and neutrophilia (white cell count $20.1 \times 10^{9} / \mathrm{L}$, neutrophils $\left.16.7 \times 10^{9} / \mathrm{L}\right)$ with persistent lactic acidosis presumed related to multifocal pneumonia. He required intubation for worsening hypoxia/adult respiratory distress syndrome and received vasopressor support for several days. Bronchoscopy demonstrated no endobronchial mass and extensive white secretions coating the airways. Bronchoalveolar lavage fluid cytology showed 95\% neutrophils and 1\% lymphocytes. Extensive infectious workup including blood cultures and bronchoalveolar lavage culture was entirely negative. Broad spectrum antibiotics, prednisone and antifungal treatment were given as an inpatient. Two weeks from admission, the patient improved enough to be discharged home with oxygen, completing an oral antibiotic course and prednisone taper. Neoplastic workup (such as peripheral blood smear, bone marrow aspirate, pulmonary biopsy) was not performed during initial presentation due to the patient's clinical improvement suggestive of community acquired pneumonia (despite negative cultures).

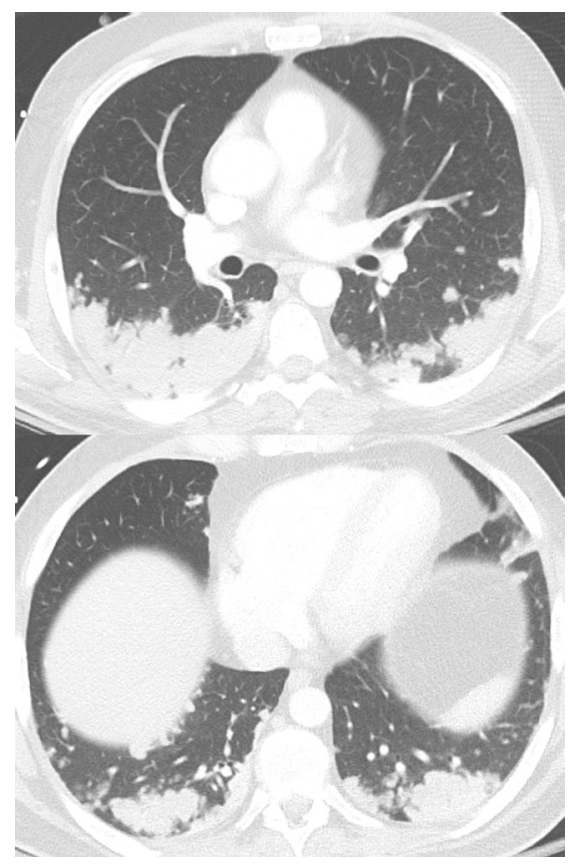

Figure 2 Axial CT images 3 weeks after initial CT examination demonstrate resolution of interstitial thickening and development of multiple dependent nodules with confluent masses in the mid lungs. 
Ten days after discharge, the patient again returned to the hospital presenting with increasing dyspnea. Repeat CT of the chest was performed (figure 2; 3 weeks after initial CT), which demonstrated resolved interstitial thickening with appearance of multiple confluent pulmonary masses in the dependent lungs. After the second CT examination raised suspicion for neoplasm, the patient underwent video-assisted thoracoscopic surgical biopsy demonstrating CD30+ T-cell lymphoma. Multiple pulmonary nodules/masses are considered the most common pattern of either primary or secondary pulmonary involvement by lymphoma, ${ }^{23}$ and cavitation or air bronchograms are

\section{Learning points}

- Although pulmonary interstitial abnormalities have a broad differential, including edema and infection, nodular peribronchovascular interstitial thickening should raise concern for lymphoma or Kaposi sarcoma involving the lungs.

- The dependent lungs are a common location of pneumonia, aspiration and atelectasis. However, due to regional differences in blood flow hematogenous processes such as pulmonary emboli, metastatic disease and seeding of lymphoma are also common in these regions of the lung.

- Multiple imaging appearances of pulmonary lymphoma, such as pulmonary nodules and nodular interstitial thickening, can occur during the clinical course of one patient. Cavitation, air bronchograms and peribronchovascular distribution are common imaging features of pulmonary lymphoma. commonly associated features. Pulmonary T-cell lymphoma may more commonly present with ground glass opacities and peribronchovascular thickening. ${ }^{4}$ The dependent predominance of findings seen in this patient and the rapid evolution from interstitial abnormalities to pulmonary masses are not previously reported in pulmonary lymphoma. The patient was started on brentuximab vedotin and CHP (cyclophosphamide/doxorubicin/ prednisone) chemotherapy for peripheral T-cell lymphoma with solid organ involvement. The patient's symptoms improved dramatically and follow-up chest CT 2 months after initiating therapy showed complete resolution of the pulmonary masses.

Contributors All authors involved in the conception of the case report. JPM: Prepared, reviewed and approved manuscript. NLL: Reviewed and approved manuscript. JAH: Identified case, reviewed and approved manuscript. MJK: Revised, reviewed and approved manuscript.

Funding The authors have not declared a specific grant for this research from any funding agency in the public, commercial or not-for-profit sectors.

Competing interests None declared.

Patient consent for publication Obtained.

Provenance and peer review Not commissioned; externally peer reviewed.

\section{REFERENCES}

1 Sirajuddin A, Raparia K, Lewis VA, et al. Primary pulmonary lymphoid lesions: radiologic and pathologic findings. Radiographics 2016;36:53-70.

2 Hare SS, Souza CA, Bain G, et al. The radiological spectrum of pulmonary lymphoproliferative disease. Br J Radiol 2012;85:848-64.

3 Lewis ER, Caskey Cl, Fishman EK. Lymphoma of the lung: CT findings in 31 patients. AJR Am J Roentgenol 1991;156:711-4.

4 Okada F, Ando Y, Kondo Y, et al. Thoracic CT findings of adult T-cell leukemia or lymphoma. AJR Am J Roentgenol 2004;182:761-7.

Copyright 2021 BMJ Publishing Group. All rights reserved. For permission to reuse any of this content visit

https://www.bmj.com/company/products-services/rights-and-licensing/permissions/

BMJ Case Report Fellows may re-use this article for personal use and teaching without any further permission.

Become a Fellow of BMJ Case Reports today and you can:

- Submit as many cases as you like

- Enjoy fast sympathetic peer review and rapid publication of accepted articles

- Access all the published articles

- Re-use any of the published material for personal use and teaching without further permission

Customer Service

If you have any further queries about your subscription, please contact our customer services team on +44 (0) 2071111105 or via email at support@bmj.com.

Visit casereports.bmj.com for more articles like this and to become a Fellow 